hearing to the addresses made and the arguments presented in favor of legal status for nurses. The deputation included Mrs. Bedford Fenwick, secretary of the State Society; Miss Haldane, of the Scottish Registration Committee; Miss Hampson, the president of the Irish Nurses' Association; Miss Peter, late Superintendent of the Queen Victoria Jubilee Institute for Nurses; Miss Pearse, Miss Mollett, Miss Barton, Miss Forrest, all representing hospital and nursing interests; and Miss Breay, the secretary of the Matron's Council. Lady Helen Munro Ferguson, whose assistance has been of a most effective and unremitting character, and Mrs. Garrett Fawcett were among the lay members, and Dr. Bedford Fenwick, Dr. H. Langley Browne, and Sir James Crichton Browne represented the medical profession. The deputation was cordially received by the president of the Privy Council, who said in his reply to the addresses that the uniform of the nurse carried with it a prestige only enjoyed in the case of "the inferior sex" by His Majesty's Navy, and it was important that its honor should be upheld. He assured the deputation that a registration bill, if introduced, would receive the "benevolent attention of the government."

Thus another important step in the highly picturesque and extraordinary road toward their goal has been taken by the nurses of Great Britain. When registration finally comes, we hope the leaders of this most determined and intelligent movement will write a complete history of its whole inception and progress.

\title{
RAISING THE STANDARD IN THE ENGLISH ARMY NURSING SERVICE
}

The English Military Nursing Service has instituted an excellent and practical examination test for matrons, and after February all sisters, before promotion to the rank of matron, will be required to pass this examination. The British Journal of Nursing summarizes the eligibility qualifications for this examination as follows:

The completion of five year's service in the rank of sister in the military service.

The submission of a certificate that, during the twelve months previous to the date on which the examination is held, the candidate has undergone special instruction by a matron in the matron's duties for a period of two months, or has discharged matron's duties for the same period. This certificate is to be signed by the matron of the hospital in which the sister is serving. 
To enable candidates to procure the necessary certificate of administrative capacity, sisters of four years service and over may at their own request undergo a two month's course of special instruction in matron's duties.

The board of examiners will consist of a principal matron as president, and two military matrons as members. For stations abroad a board will be appointed to conduct the oral examination under arrangements made by the director-general. The written examination will be supervised by a local board consisting of a matron as president and two sisters as members.

The examination will be written and oral; the written portion will consist of four questions, for which three hours will be allowed.

The time alloried for the oral portion will be fifteen minutes.

The examination will consist of questions bearing on the following subjects :

PART I. (a) The regulations affecting the army nursing service, and the relations of its members to the medical officers, nursing staff, and patients of hospitals; method of conducting official correspondence and of keeping accounts.

(b) The distribution of duties of the nursing personnel in hospitals in peace and war, and the numerical proportion of nursing staff to patients under varying circumstances.

(c) The special circumstances affecting nursing in hospitals in the field, hospital ships, ambulance trains, convalescent establishments.

(d) Responsibilities of nursing staff as to equipment, bedding, and linen.

(e) The supervision of nursing quarters and their domestic economy.

(f) The sanitation, in accordance with the regulations, of all premises under their charge; rentilation, warming, and methods of cleaning.

(g) Precautions necessary in connection with nursing of cases of infectious disease.

(h) The nursing in hospitals for women and children.

PART II. To deliver, before the examiners, a lecture adapted to the training of orderlies, royal army medical corps, on one of the subjects laid down in the syllabus contained in standing orders for royal army medical corps, Appendix 2.

The time allotted to this lecture should not exceed forty-five minutes.

Written questions on the lecture (suitable for the orderlies attending the same) must be handed in at the time of examination.

MARKS FOR THE EXAMINATION.

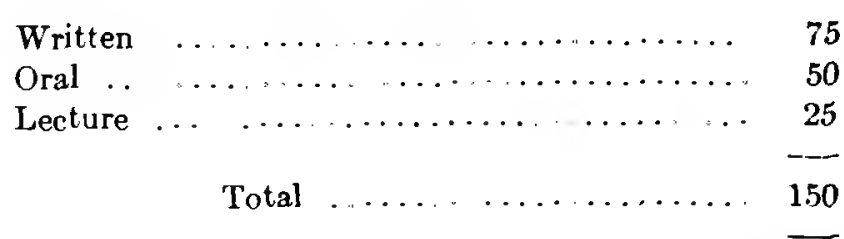

50 per cent. of the total marks are necessary to pass. 
There has died recently at the Convent, Wigton, Cumberland, in the eighty-second year of her age, one of the few remaining nurses of the Crimean War, Mother Mary de Chantal, R. R. C., known in the world as Maria Louisa Huddon. Miss Huddon entered the Convent of Mercy, Bermondsey, in the year 1851, and with other members of her community went out to the Crimea in 1854, serving for eighteen months under Miss Florence Nightingale.

Miss Margaret J. Edmunds, a graduate of the University Hospital in Ann Arbor, '94, now one of three foreign-born trained nurses in Korea, introduces us by photographs to the members of Korea's first native training-school for nurses-Miss Grace Yee, Mrs. Martha Kim, Mrs. Ella Kim and Mrs. Mattie Chung. The name of their training-school is Po Ku Nyo Koau, at Seoul, Korea.

We greet warmly these charming young Oriental sisters, and hope to hear more from Miss Edmunds of her work among them. 